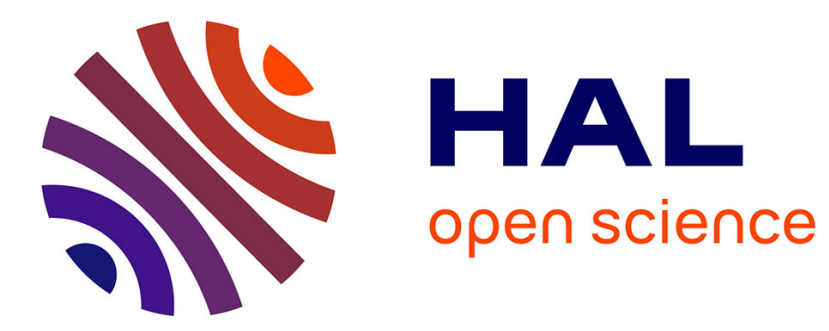

\title{
Torques from capillary cholesteric flow between coaxial cylinders
}

F. Fischer, J. Grupp

\section{To cite this version:}

F. Fischer, J. Grupp. Torques from capillary cholesteric flow between coaxial cylinders. Journal de Physique Lettres, 1984, 45 (22), pp.1091-1095. 10.1051/jphyslet:0198400450220109100 . jpa00232454

\section{HAL Id: jpa-00232454 https://hal.science/jpa-00232454}

Submitted on 1 Jan 1984

HAL is a multi-disciplinary open access archive for the deposit and dissemination of scientific research documents, whether they are published or not. The documents may come from teaching and research institutions in France or abroad, or from public or private research centers.
L'archive ouverte pluridisciplinaire HAL, est destinée au dépôt et à la diffusion de documents scientifiques de niveau recherche, publiés ou non, émanant des établissements d'enseignement et de recherche français ou étrangers, des laboratoires publics ou privés. 
Classification

Physics Abstracts

$61.30-46.90$

\title{
Torques from capillary cholesteric flow between coaxial cylinders
}

\author{
F. Fischer and J. Grupp $\left(^{+}\right)$ \\ Physikalisches Institut der Universität, Domagkstr. 75, 4400 Münster, F.R.G.
}

(Reçu le 6 juillet 1984, accepté le 21 septembre 1984)

\begin{abstract}
Résumé. - Un appareil composé de deux parois cylindriques coaxiales sert à mesurer des courants capillaires. Le cylindre intérieur est suspendu à un fil en quartz. Cet appareil permet de mettre en évidence un couple $M$ provoqué par le courant des cristaux liquides cholestériques. La valeur absolue de $M$ est en accord avec la " perméation " définie par Helfrich tandis que le courant total par unité de temps indique un haut degré de lubrification de la texture cholestérique.
\end{abstract}

\begin{abstract}
A capillary flow device whose walls are two coaxial cylinders, the inner of which is suspended on a quartz thread, allows to measure a torque $M$ caused by the flow of cholesteric liquid crystals. The magnitude of $M$ conforms to Helfrich's permeation, while flow rate and rotational shear rate indicate strong slippage of the cholesteric texture.
\end{abstract}

Investigations of the rheological behaviour of cholesteric liquid crystals which study the dependence on the shear rate are only few. Observations made by K. Sakamoto et al. [1] that with decreasing shear rate the viscosity is increased by several orders of magnitude in the cholesteric phase, as well as in the smectic phase below, inspired W. Helfrich [2] to discuss a new kind of flow (he coined it " permeation ") in order to explain these phenomena. Thereby the molecules move relative to the cholesteric texture which is thought as being blocked spatially by anchoring effects at the wall. When cholesterics flow with a velocity $v_{\mathrm{p}}$ ( $\mathrm{p}$ for permeation) along their helical axis, all molecules are simultaneously rotated and the angular velocity is $\omega=q_{0} v_{\mathrm{p}}\left(q_{0}\right.$ intrinsic twist, $q_{0}=2 \pi / p_{0}, p_{0}$ pitch). This rotational friction at uniform plug-like flow is described by the viscosity coefficient $\lambda_{1}=\alpha_{2}-\alpha_{3}$ :

$$
p^{\prime}=\lambda_{1} q_{0}^{2} v_{\mathrm{p}} .
$$

At higher pressure gradients $p^{\prime}$ along the helical axis the wall anchoring may be broken and a superposed slippage of the cholesteric texture with velocity $v_{\mathrm{t}}$ may increase the total flow velocity $v=v_{\mathrm{p}}+v_{\mathrm{t}}$.

At stationary flow through a capillary of circular cross section, the cholesteric cannot produce an axial torque to the wall. This would violate conservation of angular momentum. Torque applied by the rotating molecules has to be steadily compensated by elastic deformation of the cholesteric texture and possibly by superposed circular flow around the axis of the capillary tube.

$\left({ }^{+}\right)$Present address : Asulab S.A., Neuchâtel, Switzerland. 
We have chosen an experimental setup for capillary flow in which axial torques to the walls are made possible. We use a circular ring as capillary cross section. An inner cylinder $\left(R_{1}=2.90 \mathrm{~mm}, h=10 \mathrm{~mm}\right)$ is suspended on a quartz thread (diameter $30 \mu \mathrm{m}$, length $31 \mathrm{~cm}$ ) so that it can perform rotary oscillations around its symmetry axis. It is centred within an outer cylinder $\left(R_{2}=3.00 \mathrm{~mm}\right)$. Axial cholesteric flow induced by $p^{\prime}=\rho g+\mathrm{d} p / \mathrm{d} z$ ( $\rho g$ hydrostatic, $\mathrm{d} p / \mathrm{d} z$ external pressure gradient) through the narrow slit of width $d=R_{2}-R_{1}=(95 \pm 5) \mu \mathrm{m}$ will produce torques on both cylinders which cancel each other. By the closeness of the walls eventual circular flow and elastic deformation are practically suppressed. Only the viscous torque, caused by molecular rotation, remains. Therefore this torque around the vertical axis should be

$$
M= \pm \lambda_{1} q_{0} v_{\mathrm{p}} V
$$

where $V=2 \pi R^{2} h$ and $R=\left(R_{2}+R_{1}\right) / 2$. Relation (2) is identical to that used to measure $\lambda_{1}$ of nematics in a rotating magnetic field, a method going back to V. N. Tsvetkov [3]. We simply have to replace $\omega$ by $q_{0} v_{\mathrm{p}}$. Combining equation (2) with (1) we eliminate $v_{\mathrm{p}}$ and obtain

$$
M= \pm V p^{\prime} / q_{0} \text {. }
$$

This relation predicts a torque proportional to the pitch and therefore its validity has to be restricted to such flows where permeation still takes place. That means the helical coil must not be suppressed by wall effects. This sets a lower limit on slit width $d$.

For an exact adjustment of both cylinders the outer cylinder is aligned by a bubble level. Next the suspension of the inner cylinder is systematically shifted and each position is tested for free rotary oscillations of the inner cylinder. From that we gain the centre position. From the period of oscillation and from the inertial momentum of the inner cylinder (including the small mirror above the cylinder, which allows us to measure the angle of rotation or twist angle $\phi$ ) we obtain the torque per twist angle $M / \phi=D^{*}=7.09 \times 10^{-9} \mathrm{Nm} / \mathrm{rd}$.

These first experiments of their kind are performed without any effort of molecular aligning the sample. We use MBBA doped with $3.13 \mathrm{wt} \%$ cholesteryl chloride $(\mathrm{CC})$ which forms a lefthanded helix [4]. The eigen pitch has been determined to $q_{0}=1.03 \times 10^{6} \mathrm{~m}^{-1}$ by using Cano's wedge [5]. The total pressure difference $\Delta p_{0}=p^{\prime} \cdot h$ has been controlled with an oblique water-

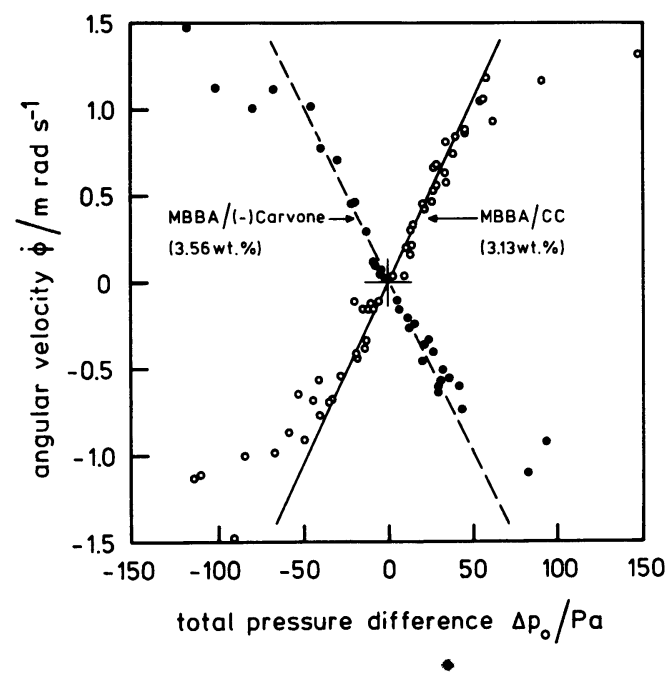

Fig. 1. - Angular velocity at zero passage $\dot{\phi}$ as a function of total pressure difference $\Delta p_{0} . \bigcirc$ (full curve) MBBA doped with $3.13 \mathrm{wt} \%$ cholesteryl chloride. (dashed curve) MBBA doped with $3.56 \mathrm{wt} \%$. (-) Carvone. 
filled $U$ tube manometer connected to the lower end of the flow cell. The upper end was open to air.

Figure 1 (full curve) shows $\dot{\phi}$, the angular velocity at zero passage as a function of $\Delta p_{0}$. It came out that for larger $\left|\Delta p_{0}\right|$ the stationary maximum twist angle $\phi_{\mathrm{m}}$ could not be reached, because of a (possibly) hydrodynamic instability which displaces the inner cylinder off axis so that it touches the outer cylinder. But by reversing the pressure gradient it got loose again which was indicated by a transient movement of the reflected laser beam in vertical direction. By this way data points of alternating signs have been collected.

Figure 2 shows the total flow rate $Q$ as a function of $\Delta p_{0}$. Rate $Q$ was determined from the velocity of the liquid crystal filament in a horizontal capillary tube at the lower end of the flow cell. Its cross section of $1.32 \mathrm{~mm}^{2}$ was obtained by measuring the mass and the length of a mercury droplet when brought into the tube.

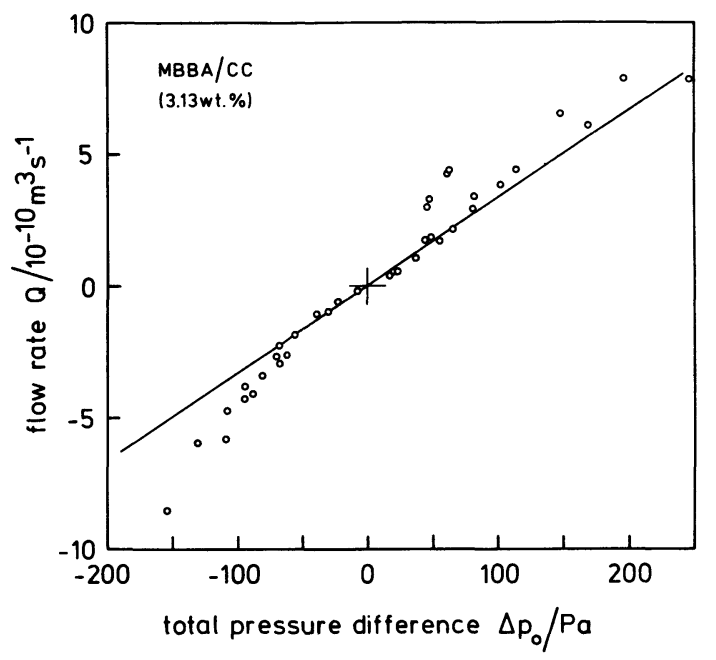

Fig. 2. - Total flow per second $Q$ as a function of $\Delta p_{0}$.

In figure 3 you find, restricted to a smaller pressure range, equilibrium values $\phi_{\mathrm{m}}$ as a function of $\Delta p_{0}$. For higher values of $\left|\Delta p_{0}\right|$ we could not get data because before $\phi_{\mathrm{m}}$ was reached the inner cylinder was shifted aside. For all three measurements we had to take care that the meniscus edge of the liquid crystal filament had to be at the same position (to within $10 \mathrm{~mm}$ ) in order to make sure that the upper level of the liquid crystal always had the same height. The data show sufficient reproducibility for small $\left|\Delta p_{0}\right|$. They can be represented by straight lines through the origin. At higher $\left|\Delta p_{0}\right|$ we observe systematic deviations towards reduced permeation and reduced flow resistance.

In order to confirm this torque effect as intrinsic to cholesteric flow and to exclude eventual systematic errors from the capillary wall (all walls had been finely polished after machining on the lathe) we applied the following tests. Heating MBBA/CC above its clearing point causes the torque effect to disappear. Replacing MBBA/CC by MBBA/(-) Carvone $(3.56 \mathrm{wt} \%$ ), which has a right-handed helix [6], produces the reverse torque as seen in figure 1 (dashed curve).

From figures 1 to 3 we take the slope of the straight lines for MBBA/CC :

$$
\begin{aligned}
\left(\dot{\phi} / \Delta p_{0}\right)_{\exp } & =2.10 \times 10^{-5} \mathrm{rd} / \mathrm{sPa} \\
\left(Q / \Delta p_{0}\right)_{\exp } & =3.33 \times 10^{-12} \mathrm{~m}^{3} / \mathrm{sPa} \\
\left(\phi_{\mathrm{m}} / \Delta p_{0}\right)_{\exp } & =3.65 \times 10^{-3} \mathrm{rd} / \mathrm{Pa}
\end{aligned}
$$




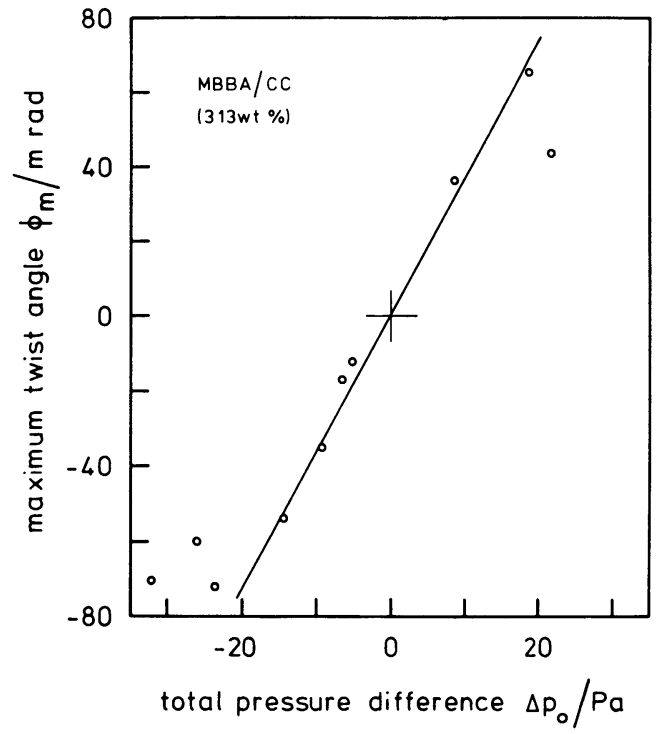

Fig. 3. - Stationary torsional angle $\phi_{\mathrm{m}}$ as a function of $\Delta p_{0}$.

Equation (6) allows a direct comparison with equation (3). We obtain $\left(M / p^{\prime}\right)_{\exp }=2.59 \times$ $10^{-13} \mathrm{~m}^{4}$ rd while $\left(M / p^{\prime}\right)_{\mathrm{th}}=2.65 \times 10^{-13} \mathrm{~m}^{4} \mathrm{rd}$. The surprisingly high degree of agreement should be more incidental. Another view is presented if we compare equation (5) to equation (1) $\left(\lambda_{1}=-0.143 \mathrm{sPa}\right.$ for pure MBBA [7]). We obtain $\left(Q / p^{\prime}\right)_{\exp }=3.33 \times 10^{-14} \mathrm{~m}^{4} / \mathrm{sPa}$, whereas $\left(Q / p^{\prime}\right)_{\mathrm{th}}=1.16 \times 10^{-17} \mathrm{~m}^{4} / \mathrm{sPa}$, which means 2900 times more than expected for plug-like flow. This discrepancy is a reproducible intrinsic effect. It must be caused by the fact, that the flow rate is mainly given by the slippage of the cholesteric texture. Nevertheless, permeation described by equation (1) is persisting.

To complete this picture let us determine two viscosities out of our data. An average shear viscosity $\bar{\eta}$ is obtained from the angular velocity $\phi$ of the inner cylinder, which causes simple shear flow between both cylinders. With data of equations (4) and (6) we find

$$
\bar{\eta}=\left(\phi_{\mathrm{m}} / \dot{\phi}\right)_{\mathrm{exp}} \cdot\left(D^{*} d / 2 R^{3} h\right)=0.076 \text { Pas }
$$

This is the same magnitude as that of known viscosity coefficients of MBBA. An apparent viscosity $\eta_{\text {app }}$ is obtained by comparing $Q$ out of equation (1) with that of Hagen-Poiseuille flow :

$$
\eta_{\mathrm{app}}=\left|\lambda_{1}\right| \cdot d^{2} q_{0}^{2} / 12 \text {. }
$$

For our case this should give $\eta_{\mathrm{app}}=884\left|\lambda_{1}\right|$; actually according to the factor of 2900 , we only find $\eta_{\text {app }}=0.3\left|\lambda_{1}\right|$. So both viscosities show normal magnitude without any hint to permeation.

Permeation is certainly demonstrated by the measured torques and by their agreement with equation (3). The apparent coexistence of ordinary shear flow is hard to understand. However, as long as shear flow of the texture will not reduce those elastic stresses (between the boundaries and the interior of the cholesterics) which are necessary for permeation, the pressure gradient $p^{\prime}$ will simultaneously feed both channels of flow $\left(v_{\mathrm{t}}\right.$ and $\left.v_{\mathrm{p}}\right)$. That means, during ordinary shear flow of the texture there is a permeation of the molecules relative to the texture taking place. If the helical axis varies within the capillary, as in a focal conic texture, the expected torque could be slightly reduced. There seems to be no leakage path with strong loss of permeation. Because of its statistical nature this also would give more scattering in the data. A beginning leakage 
possibly caused by flow alignment may be indicated by the deviations of the data points from the straight lines in figure 1 and 2 , when $\left|\Delta p_{0}\right|$ exceeds about $50 \mathrm{~Pa}$. We will extend our measurements by varying $q_{0}, d$, and $V$ in order to further test relations (1)-(3). Microscopic studies of cholesteric flow rates with still smaller pressure gradients are worth-while and will be performed soon. Then well defined alignments of the helical axis relative to the flow direction will be used.

\section{References}

[1] Sakamoto, K., Porter, R. S. and Johnson, I. F., Mol. Cryst. Liq. Cryst. 8 (1969) 443.

[2] Helfrich, W., Phys. Rev. Lett. 23 (1969) 372.

[3] Tsvetkov, V. N., Acta Physicochim. URSS X (1939) 555.

[4] Saeva, F. D. and Wysocki, J. J., J. Am. Chem. Soc. 93 (1971) 5928.

[5] Cano, R., Bull. Soc. Fr. Mineral. Cristallogr. 90 (1967) 333.

KassubeK, P. and Meier, G., Mol. Cryst. Liq. Cryst. 8 (1969) 305.

[6] WAHL, J., in Liquid Crystals, Chandrasekhar ed. (London) 1980, p. 267.

[7] Kneppe, H., Schneider, F. and Sharma, N. K., J. Chem. Phys. 77 (1982) 3203. 